\title{
Preventing hearing loss from portable music player use
}

Singapore Med J 2014; 55(3): 171-172 doi:10.11622/smedj.2014045

We refer to Lee et al's ${ }^{(1)}$ survey of 1,928 polytechnic students in Singapore, which found that $16.4 \%$ of their participants listened to portable music players (PMPs) at levels that place the listener at risk of noise-induced hearing loss. We agree with the authors that there is a need for preventive measures to avoid a potential epidemic of noise-induced hearing loss from inappropriate PMP use.

Current PMPs, which include smartphones and tablets, are able to store hundreds of audio and video files, produce less noise distortion at high volumes, and have a longer battery life than older devices. These devices are popular among the younger generation, who often listen to their audio and video files at loud volumes and for long periods of time through their headsets, taking their hearing for granted. The European Union (EU) Scientific Committee on Emerging and Newly Identified Health Risks (SCENIHR) found that $5 \%-10 \%$ of PMP listeners risk permanent hearing loss if they listen to PMPs at high volume settings for more than one hour per day over a period of at least five years.(2) Current European safety standard restricts the noise level of PMPs to $100 \mathrm{~dB}$. However, maximum decibel levels can differ from model to model, and some can produce up to $129 \mathrm{~dB}$ of sound.

A mandate proposed by the European Commission requires manufacturers of all PMPs and mobile phones with a music playing function to provide a safe exposure limit in their "default" settings. ${ }^{(3)}$ All PMPs sold in the EU after February 2013 must have a default sound limit of $85 \mathrm{~dB}$. If users override the limit, a warning about the risk is repeated every 20 hours of listening time. ${ }^{(4)}$

Simply asking young persons to reduce the volume of their PMPs may not work. One study reported that teenagers who were pressured to reduce the volume of their iPods turned up the volume instead. ${ }^{(5)}$ Thus, to reach out to this group of individuals, innovative measures are needed. One example of an innovative approach is the use of a sound measuring mannequin to demonstrate the sound levels produced by PMPs. Such a mannequin, named Jolene, has been developed (www.dangerousdecibels.org). A study using Jolene indicated that $16 \%$ of $14-18$ year olds were listening to their personal stereo systems at levels and durations that exceeded National Institute for Occupational Safety and Health's recommended exposure levels on a daily basis. After the encounter with Jolene and her student educator, $44 \%$ of those who regularly exceeded the recommended noise exposure levels responded that they intended to lower the listening volumes on their devices in the future. ${ }^{(6)}$

Jolene was first introduced in multiethnic Singapore at the 2012 Eastern Health Alliance Scientific Meeting. The public's response to Jolene was overwhelmingly positive. However, one useful feedback received was that the use of a mature, adult, white female mannequin that consisted of only the upper half of the body was not ideal, as the target population of young persons of various ethnic groups could not readily identify with such a mannequin. A common question asked was, "Why the name Jolene?" Some wondered if the name had any special significance or was an acronym for something meaningful. In response to this feedback, staff from the departments of otolaryngology and biomedical engineering, Changi General Hospital, Singapore, developed two sound measuring mannequins, Max and Belle. These mannequins made their first appearance together with Jolene in 2013. Max is a cute-faced, whole-body, child-sized male mannequin, while Belle is a stylishly dressed, dark-complexioned, adolescent, whole-body, female mannequin (Fig. 1).

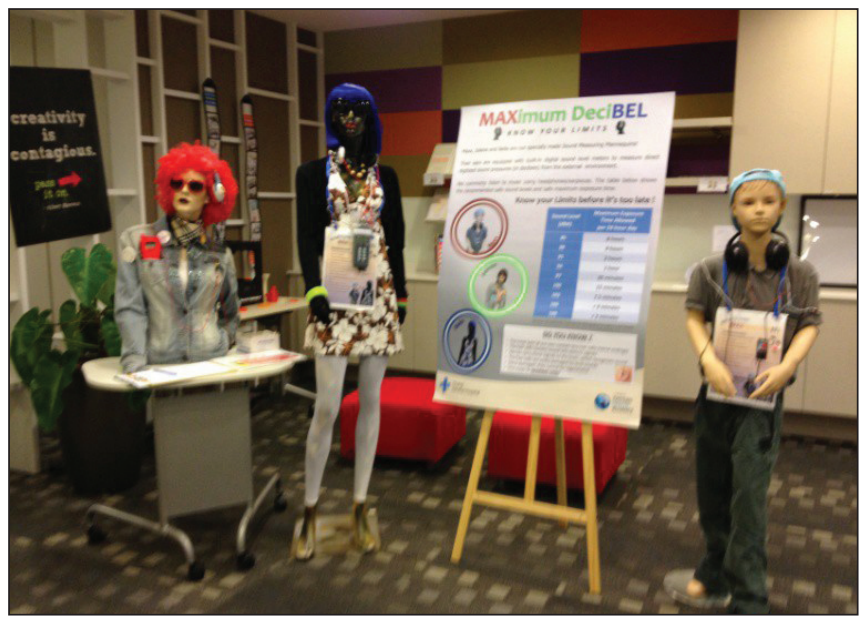

Fig. 1 Photograph shows Jolene, Belle and Max at the Eastern Health Alliance Scientific Meeting 2013. 
Max and Belle, both socially and culturally appropriate to Singapore, have been well received by the public. Their names represent "MAXimum deciBELs", which is part of the educational message that was to be imparted. PMP users were asked to put their earpieces into the mannequins' ears at different volume settings. The reading in decibels informed the PMP users of the sound level produced by their PMPs at their usual listening volume and the maximum volume of the player. The user could then compare this information with recommended standards for allowable duration of exposure. They were also given an explanation on how the risk of hearing loss increases with the loudness of sound from earphones or headphones and the length of listening time. Max and Belle are now on display at the public patient waiting area in the Ear, Nose and Throat outpatient clinic in Changi General Hospital. They serve as a patient education model and are part of our ongoing efforts to prevent hearing loss from PMP use among youths in Singapore.

Yours sincerely,

David Koh',2,3, Joyce Jeanne Lim', Peter Lu'

${ }^{1}$ Department of Otolaryngology, Changi General Hospital, Singapore, ${ }^{2}$ PAPRSB Institute of Health Sciences, University Brunei Darussalam, Brunei, ${ }^{3}$ Saw Swee Hock School of Public Health, National University Health System, National University of Singapore, Singapore.david_koh@nuhs.edu.sg

\section{REFERENCES}

1. Lee JC, Lim MY, Kuan YW, et al. The music listening preferences and habits of youths in Singapore and its relation to leisure noise-induced hearing loss. Singapore Med J 2014; 55:72-7.

2. European Commission. Scientists warn of health risks from exposure to noise from personal music players. October 13,2008 [online]. Available at: http:// europa.eu/rapid/press-release_IP-08-1492_en.htm. Accessed February 18, 2014.

3. European Commission. Consumers: EU acts to limit health risks from exposure to noise from personal music players. September 28,2009 [online] Available at: http://europa.eu/rapid/press-release_IP-09-1364_en.htm?locale=en. Accessed Febraury 18, 2014.

4. BBC News. Fears that music volume limit 'could be ignored'. February 4, 2013 [online]. Available at: www.bbc.co.uk/news/health-21294537. Accessed February 18, 2014

5. Portnuff, C, Fligor B, Arehart K. Teenage use of portable listening devices: a hazard to hearing? Presentation at Annual Conference of the National Hearing Conservation Association. Atlanta, GA 2009.

6. Martin WH, Martin GY. Meet Jolene: An inexpensive device for doing public health research and education on personal stereo systems. Presented at Hearing loss: 9th International Congress on Noise as a Public Health Problem (ICBEN), Foxwoods, CT, 2008. 